\title{
Visual Manipulative: It's Effectiveness in Improving the Academic Performance of Grade 10 Students in Music
}

\author{
Rayvin D. Pestano ${ }^{1}$ \\ ${ }^{1}$ Faculty, Institute of Sports, Physical Education and Recreation, College of Education, \\ Central Luzon State University, Science City of Munoz, 3119, Nueva Ecija, Philippines
}

\begin{abstract}
:
This study aimed to find the effectiveness of visual manipulative in teaching music among grade 10 students in Juan R. Liwag Memorial High School. Forty-five students were used in this study. Pre-test and post-test were administered to the respondents. Data were recorded. The respondents were subjected to the intervention using visual manipulative and pre-test and post-test were provided for them to measure the improvement of their academic performance. Results of pre-test and post-test were analyzed using paired sample t-test. Based on the data gathered with regards to the score of the students after giving the intervention-visual manipulative, it showed significant difference in terms of post-test scores. There is a significant difference in the post-test between the students who were subjected in the intervention- visual manipulative.
\end{abstract}

Keywords Visual Manipulative, Music Teaching, Academic Performance

\section{Introduction}

Music is "the art of combining tones to form expressive composition; any rhythmic sequence of pleasing sounds" according to Webster New World Dictionary. But it is more than just definition, music enable us to express our feelings, emotions and ideas. Music can be a way of communication that brings people together. Hence, education recognize the vital role of music in people's lives (Ibarra, 2015). As a result, music is included in the curricula.

In the Department of Education (DepEd) context of educational curriculum in elementary and junior high school, music is integrated and part of subject called MAPEH- Music, Arts, Physical Education and Health. MAPEH teachers in junior high school are responsible in teaching its components.

Furthermore, MAPEH teachers are expected to have high level of teaching competencies in the four domains of MAPEH. Each teacher should manifest certain level of acquired skills and knowledge both in applied and knowledge-based facts in all components. This is to ensure the quality of instruction in the transmission of knowledge to students. However, MAPEH teachers encounters challenges and struggles in teaching one of MAPEH's component parts -
Music. While Music is considered an academic discipline and must be recognized as such (Atabug, 2006), learners academic performance might be affected by the teacher's acquired skills, knowledge and strategies in teaching specific musical concepts (Ibarra, 2015).

It is imperative for the teacher to have wide range of knowledge in using different teaching strategies. It is evident in the field of education that there is a relationship between applying teaching strategies and effective learning in the classroom (Onwe \& Akpan 2014). Thus, in order to promote learning in music, an effective teacher must have a number of approaches and strategies that can influence the performance and achievement of students.

Because music teaching and learning is competency-based approach, the content of the general music for secondary curriculum also anchored in the required learning competencies in music education for the K-12 program. This would be a set of defined behaviors that provide a structured guide enabling the identification, evaluation and development of the learning behavior of individual music learner. Capable of understanding musical concepts, teaching music competently in the general music class necessitates 
good choice of teaching strategy and the aptitude to classroom activities (Ibarra, 2015).

Contained in grade 10 music are topics like impressionism, expressionism, afro-latin and popular music, contemporary Philippine music and $20^{\text {th }}$ and $21^{\text {st }}$ century multi-media forms (RBEC 2013). Primary and secondary elements are also included in the content for instruction using a spiral approach that gradually increases the level of difficulty. As topics progress from simple to complex, MAPEH teachers' teaching strategies and approaches are imperative to sustain the quality of music instruction.

This led the researcher to conduct an action research to find the effectiveness of visual manipulative in improving the academic performance in music of grade 10 students in Juan R. Liwag Memorial High School.

\subsection{Research Objectives}

To describe the academic performance of the of grade 10 learners in music before they were subjected to visual manipulative.

To determine the academic performances of grade 10 learners in music after they were subjected to visual manipulative.

To determine the effectiveness of visual manipulative in enhancing the academic performance of grade 10 student.

\subsection{Research Hypothesis}

There is no significant difference in the academic performance of grade 10 students in music after they were subjected to visual manipulative intervention.

\subsection{Study Significance}

To the School Head: As the administrator of the school, it is necessary that they are aware on the academic performance of the students. Furthermore, it is important that they monitor the teaching strategies of the teachers used in teaching music.

To the Teachers: Teachers should consider innovative strategies in teaching music. It would be useful for them to think for new ideas and techniques that would enhance their pedagogy in teaching music, thus improving the academic achievement of learners.
To the Students: As the benefactors of this research, it will help them give more importance to their academic performance in music. Also, this study will assist them appreciate the music subject thus increasing their interest and academic achievement.

To the Future Researchers: All researchers interested in this field of study may use this findings as they investigate other aspects of this research project.

\subsection{Research Terminologies}

The following operational terms were used to describe the variables in this study.

Academic Performance- this refers to the measure of final grade earned in the subject. Also it is defined as the total score or grade point which is attained by learners.

Effectiveness- this refers to the degree to which something is useful or successful in producing the desired results.

Grade 10- refers to the students in tenth grade in K12 program. They are the subject of the study.

Manipulatives- are physical objects that are used as teaching tools to engage students in the hands-on learning. They can be used to introduce, practice, or remediate a concept.

Pre-Test- a preliminary test administered to determine a student's baseline knowledge or preparedness for an educational experience or course of study.

Post-Test- an achievement test administered after a course of instruction. Also, a test given to students after completion of an instructional program or segment and often used in conjunction with a pretest to measure their achievement and the effectiveness of the program.

Quasi-experimental- an experimental research design use to estimate the causal impact of an intervention on its target population without random assignment 
Visual Aids- this refers to the things that you can look at, such as a film, model, map, or slides, to help you understand something or to remember information.

Visual Manipulative- this refers to the teaching aids, anything that can be seen like pictures, charts, etc. and that can also be physically touch, handled or manipulate.

\section{Body}

This study utilized the quasi-experimental method of research. It is an empirical interventional study used to estimate the causal impact of an intervention on its target population without random assignment.

Quasi-experimental research shares similarities with the traditional experimental design or randomized controlled trial which has control group and experimental group, but it lacks the element of random assignment to treatment or control. Instead, quasi-experimental designs typically allow the researcher to control the assignment to the treatment condition, but using some criterion other than random assignment.

The participants of this study were the grade 10 students of Juan R. Liwag Memorial High School this School Year 2018-2019. Since this research is quasi-experimental, no random assignment was done. Instead, the researcher chose among sections that were used as respondents of this study. Forty-five students consist the population of this study.

Total population sampling was used in this two sections of this study. Specifically, Bernard (2006) defines total population sampling as a sampling technique that involves examining the entire population (i.e., the total population) that have a particular set of characteristics (e.g., attributes/traits, experience, knowledge, skills, exposure to an event, ect.) creating a total population sample.

The undertakings of this action research were communicated to the department head and the principal. Letter of request was sent for the approval of the research committee of the city schools division before the full conduct of this research.

Pre-test was administered to obtain needed data. Sections were grouped as control and experimental group. Intervention: Visual Manipulative were given to the experimental group during the implementation of the intervention
For the interpretation and analysis of the data, the following statistical tools were used;

Mean. Mean central tendency were used to measure the significant difference of the academic performance through visual manipulative.

T-test. It is a statistical examination of two population means. A two-sample t-test examines whether two samples are different and is commonly used when the variances of the two normal distributions are unknown and when an experiment uses a small sample size.

\section{Result and Discussion}

Based on the results of the study on the effectiveness of visual manipulative in improving the academic performance ef grade 10 students, the following results are gathered:

\section{Chart 1. Result of Pre-Test of Control Group}

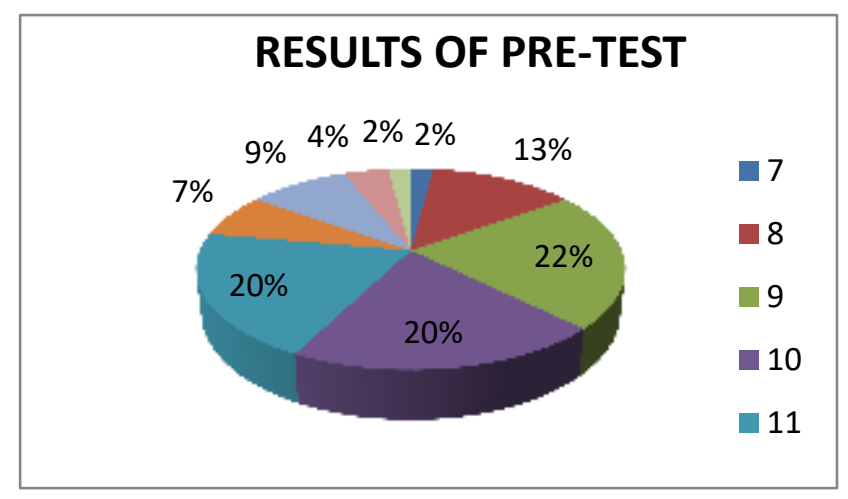

Chart 1 presents the pre-test results of the respondents. It can be seen from the data that the lowest score obtained by the respondents under this group is 7, and the highest score obtained by the respondents is 15. From the graph, one or equivalent to two percent obtained a score of seven, six or $13 \%$ obtained a score of 8,10 or $22 \%$ obtained a score of 9,10 or $20 \%$ obtained a score of 10 , while 9 or $20 \%$ obtained a score of 11 , three or seven percent obtained a score of 12 , four or nine percent obtained a score of 13 , two or four percent obtained a score of 14, and one or two percent obtained a score of 15 . 


\begin{tabular}{|l|l|l|l|l|l|}
\hline st & & & & & \\
\hline
\end{tabular}

Chart 2. Result of Post-Test of Control Group

\begin{tabular}{|c|c|}
\hline \multirow[t]{8}{*}{$\begin{array}{l}\text { Results of Post test } \\
\text { (Control Group) }\end{array}$} & \\
\hline & 17 \\
\hline & $\| 18$ \\
\hline & $=19$ \\
\hline & $=20$ \\
\hline & 121 \\
\hline & $=22$ \\
\hline & $=24$ \\
\hline
\end{tabular}

Chart 2 shows the post test results of the respondents. It can be seen from the data that the lowest score obtained by the respondents under this group is 17 , and the highest score obtained by the respondents is 24 . From the graph four or equivalent to nine percent obtained a score of 17 , eight or $18 \%$ obtained a score of 18 , four or 9 percent obtained a score of 19 , nine or $20 \%$ obtained a score of 20 , while 7 or $16 \%$ obtained a score of 21 , four or nine percent obtained a score of 22 , six or $13 \%$ obtained a score of 23 , and three or seven percent obtained a score of 24 .

Table 1. Result of Paired Sample T-Test

Paired Sample Statistics

\begin{tabular}{|l|l|l|l|}
\hline & Mean & N & Std. Deviation \\
\hline Pair & & & \\
Pre-Test & 10.30 & 45 & 6.191 \\
Post-Test & 20.24 & 45 & 5.232 \\
\hline
\end{tabular}

Paired Samples Correlation

\begin{tabular}{|l|l|l|l|}
\hline & N & Correlation & Sig. \\
\hline Pair 1 & 45 & 4.35 & .001 \\
Pre-Test & & & \\
Post-Test & & & \\
\hline
\end{tabular}

Paired Samples Test

\begin{tabular}{|l|l|l|l|l|l|}
\hline & \multicolumn{5}{|c|}{ Paired Differences } \\
\hline Pair 1 & Mea & Std. & T & df & Sig. \\
Pre-Tes & $\mathrm{n}$ & Dev. & -8.333 & 59 & .000 \\
$\mathrm{t}$ & -7.4 & 5.2 & & & \\
Post-Te & 01 & & & & \\
\hline
\end{tabular}

Paired sample $t$-test was computed to determine whether the Mean posttest of the students who were taught using visual manipulative significantly differs with the Mean pretest. Results show that the Mean posttest $($ Mean $=20.24, \mathrm{SD}=5.232)$ is significantly higher than the Mean pretest (Mean = 10.30, $\mathrm{SD}=6.191), t_{(44)}=-8.40, \mathrm{p}<.001$. The null hypothesis is rejected. It implies that the visual manipulative intervention have significant effect on the post-test scores.

\section{Conclusion}

Based on the results of pre-test and post-test and paired sample t-test, it is indicated that visual manipulative is an effective intervention in enhancing the academic performance of students in music.

\section{Recommendation}

It is highly recommended that Music teachers should use visual manipulative in teaching the said subject. Furthermore, other topics in music must also be explored using this intervention.

\section{Acknowledgement}

No external financial support was received for this study. The author would like to thank all the respondents who participated in this study.

\section{References}

1. Atabug, Alejandra C. (2006). Readings in Music Education. University of Santo Tomas, Manila. UST Printing Press.

2. Bernard, R. H. (2006). Research Method in Anthropology. New York, NY: Altamira Press.

3. Ibarra, F. P. (2015). Academic Achievement Motivation in Choosing an Instrument to Play. Education Digest, 14: 41-50.

4. Onwe, V. \& Akpan, U. (2014) "Instructional Strategies and Students Academic Performance in Electrical Installation in Technical Colleges in Akwa Ibom State: Instructional Skills for Structuring Appropriate Learning Experiences for Students". Unversity of Uyo, Nigeria. 